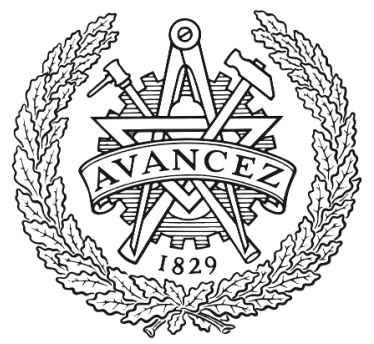

CHALMERS

UNIVERSITY OF TECHNOLOGY

\title{
Chemistry of supported palladium nanoparticles during methane oxidation
}

Downloaded from: https://research.chalmers.se, 2023-04-26 12:59 UTC

Citation for the original published paper (version of record):

Nilsson, J., Carlsson, P., Fouladvand, S. et al (2015). Chemistry of supported palladium nanoparticles during methane oxidation. ACS Catalysis, 5(4): 2481-2489. http://dx.doi.org/10.1021/cs502036d

N.B. When citing this work, cite the original published paper. 


\title{
Chemistry of supported palladium nanoparticles during methane oxidation
}

Johan Nilsson, ${ }^{*}, \dagger+\ddagger$ Per-Anders Carlsson, ${ }^{\dagger, \ddagger}$ Sheedeh Fouladvand, ${ }^{\dagger, \ddagger}$ Natalia M. Martin, ${ }^{\dagger, \ddagger}$ Johan Gustafson, $₫$ Mark A. Newton, ${ }^{\S}$ Edvin Lundgren, $₫$ Henrik Grönbeck, $\|, \ddagger$ and Magnus Skoglundh ${ }^{\dagger, \ddagger}$

Applied Surface Chemistry, Department of Chemical and Biological Engineering, Chalmers University of Technology, SE-41296 Göteborg, Sweden, Competence Centre for Catalysis, Chalmers University of Technology, SE-412 96 Göteborg, Sweden, Division of Synchrotron Radiation Research, Lund University, Box 118, SE-221 00 Lund, Sweden, ESRF, 71 Rue des Martyrs, 38000 Grenoble, France, and Department of Applied Physics, Chalmers University of Technology, SE-41296 Goteborg, Sweden

E-mail: johan.nilsson@chalmers.se

\begin{abstract}
Time-resolved in situ energy-dispersive X-ray absorption spectroscopy and mass spectrometry have been used to correlate changes in chemical state of alumina and ceria supported palladium nanoparticles with changes in activity and selectivity for methane oxidation. Specifically, modulation excitation spectroscopy experiments were

\footnotetext{
*To whom correspondence should be addressed

$\dagger$ Applied Surface Chemistry, Department of Chemical and Biological Engineering, Chalmers University of Technology, SE-412 96 Göteborg, Sweden

$\ddagger$ Competence Centre for Catalysis, Chalmers University of Technology, SE-412 96 Göteborg, Sweden

『Division of Synchrotron Radiation Research, Lund University, Box 118, SE-221 00 Lund, Sweden

$\S$ ESRF, 71 Rue des Martyrs, 38000 Grenoble, France

"Department of Applied Physics, Chalmers University of Technology, SE-41296 Goteborg, Sweden
} 
carried out by periodically cycling between net-reducing and net-oxidizing reaction conditions. The XANES and EXAFS data show that the palladium nanoparticles were readily bulk oxidized when exposed to oxygen, forming a PdO-like phase, and reduced back to a reduced (metal) phase when oxygen was removed from the feed. The difference between the two support materials was most noticeable at the switches between net-oxidizing and net-reducing reaction conditions. Here, a brief reduction in conversion was observed for the alumina supported catalyst, but for the ceria this reduction in conversion was minor or not observed at all. This difference was attributed to differences in the oxidation kinetics and the oxygen storage capability of ceria.

\section{Introduction}

Natural gas is available in abundant quantities and is widely utilized in energy conversion processes. Combustion of natural gas, where the principal component is methane $\left(\mathrm{CH}_{4}\right)$, produces low levels of pollutants such as nitrogen and sulfur oxides, and particulates compared to other fossil fuels ${ }^{1,2}$. Furthermore, less carbon dioxide $\left(\mathrm{CO}_{2}\right)$ is formed per produced quantity of energy when combusting methane compared to other hydrocarbons ${ }^{3,4}$. There is also potential to further reduce net $\mathrm{CO}_{2}$ emissions by substituting natural gas with methane-rich biogas produced from biological feedstocks ${ }^{5}$. Methane is, however, a strong greenhouse gas ${ }^{6}$ and emissions from combustion processes must be carefully controlled to avoid detrimental methane slip. Here we focus on the conversion of methane through catalytic total oxidation, which is an important technique for emission abatement in, for example, automotive applications.

Methane is the most difficult hydrocarbon to oxidize catalytically and thus relatively high temperatures are required for the reaction to proceed with an acceptable rate. The rate-limiting step in the reaction is generally considered to be the abstraction of the first hydrogen in the dissociative adsorption of methane ${ }^{7}$. Palladium has shown high activity for methane oxidation and is commonly used in catalysts. High activity for methane oxidation 
in palladium based catalysts have been attributed to reduced (metallic) palladium ${ }^{8,9}$, metal supported surface oxide ${ }^{10}$, or bulk metal oxide ${ }^{11,12}$. These conflicting reports can be related to the fact that the performance is sensitive to several catalyst parameters, such as morphology, support material, and pretreatment ${ }^{13-15}$. This shows that there is a clear need for in situ characterization to better understand the behavior of palladium catalysts for methane oxidation. Recent in situ studies have reported ${ }^{13,16}$ that methane dissociates readily over palladium catalysts when palladium is in the oxidized $\mathrm{PdO}$ phase, and also when palladium is in its metallic state, after $\mathrm{PdO}$ has decomposed at high temperature. Previously richlean cycling experiments have been performed for methane oxidation over Pd nanoparticles supported on alumina $\left(\mathrm{Al}_{2} \mathrm{O}_{3}\right)$ and ceria $\left(\mathrm{CeO}_{2}\right)^{17}$. The results from these experiments indicate that the changes in methane conversion observed when dynamically changing inlet gas conditions are strongly connected to oxidation and reduction of the active palladium phase.

The ceria support was found to promote the activity during rich-lean cycling and understanding this behavior is relevant to, for example, the use of ceria as an oxygen storage material in automotive catalysis ${ }^{18}$. In the present study we aim to extend our knowledge of palladium catalysts for methane oxidation during transient conditions by performing rich-lean cycling experiments combined with in situ dispersive X-ray absorption spectroscopy (ED-XAS) to monitor the state of the active Pd phase during the catalytic reaction.

X-ray absorption spectroscopy, also referred to as X-ray absorption fine structure (XAFS), is a powerful technique for investigating the structure and chemical properties of condensed matter. It is used to study many different types of materials, used in, for example, chemical sensors, semiconductors, and catalysts ${ }^{19}$. Information on the local geometry surrounding the absorbing atom, including bond lengths, can be obtained by analyzing the extended X-ray absorption fine structure (EXAFS) region in the spectra. The X-ray absorption near edge structure (XANES) close to the absorption edge provides information about the electronic structure of the absorbing atom, which can be used to monitor the chemical state of the 
catalytically active phase.

Modulation excitation spectroscopy ${ }^{20}$ (MES) experiments are performed in the present study by periodically changing the gas composition between net-reducing and net-oxidizing conditions. This generates spectroscopic data suitable to be analyzed by the phase sensitive detection (PSD) technique. PSD is a powerful technique through which a high degree of differentiation between active species and so-called spectator species can be obtained. Species that are involved in the catalytic reaction are expected to change reversibly and periodically with time. The time-resolved spectra collected during the experiment are averaged over the number of pulse sequences. This new set of time-resolved spectra has the duration $\tau$ which is defined as the time required to complete one pulse sequence. The key feature of this method is the use of the phase sensitive detection (PSD) analysis described by the equation

$$
A_{k}^{\phi^{P S D}}(e)=\frac{2}{\tau} \int_{0}^{\tau} A(e, t) \sin \left(k \omega t+\phi_{k}^{P S D}\right) \mathrm{d} t
$$

$A_{k}^{\phi^{P S D}}(e)$ is referred to as the phase-resolved or demodulated spectra associated with the frequency $k \omega$ ( $k=1$ corresponding to the fundamental frequency, i.e., to the frequency of excitation). $A(e, t)$ is the response of the system to the applied excitation at energy $e$ and at time $t$, and $\phi_{k}^{P S D}$ is the phase angle selected for demodulation. Treating a set of time-resolved spectra using eq 1 produces a new set of spectra called phase-resolved or demodulated spectra at different demodulation phase angles. These demodulated spectra have three advantageous properties ${ }^{21}$. First, they contain only the contribution from species that respond to the external stimulation with the same frequency, which gives a significant increase in sensitivity to active species that respond to the stimulation compared to static signals produced by spectator species. Second, the signal-to-noise ratio is vastly improved as noise has a different response frequency and will be suppressed in the demodulated spectra. Third, in principle, signals with different kinetics can be more clearly differentiated ${ }^{20,21}$. 
In the present study, rich-lean cycling experiments have been performed for methane oxidation over $\mathrm{Pd} / \mathrm{Al}_{2} \mathrm{O}_{3}$ and $\mathrm{Pd} / \mathrm{CeO}_{2}$ catalysts with in situ ED-XAS measurements. The outlet concentrations from the sample cell were monitored with mass spectrometry. The XAS spectra collected were analyzed using phase sensitive detection and EXAFS analysis to monitor the chemical state of palladium during the catalytic reaction.

\section{Experimental Methods}

The synthesis of the alumina and ceria supported Pd catalysts has been described elsewhere $^{17}$. In brief $250 \mathrm{mg}$ of either $\gamma$-alumina (Puralox SBa 200, Sasol) or ceria (99.5 H.S.A. 514, Rône-Poulenc) was added to $114 \mathrm{mg}$ aqueous solution of tetraamminepalladium(II) nitrate $\left(4.6 \mathrm{wt} \%\left(\mathrm{NH}_{3}\right)_{4} \mathrm{Pd}\left(\mathrm{NO}_{3}\right)_{2}\right.$, Johnson Matthey) as the palladium precursor to yield a $\mathbf{P d}$ loading of $\mathbf{2 \%}$. The $\mathrm{pH}$ was adjusted to 11 by addition of diluted ammonia solution. The resulting paste was continuously mixed for $15 \mathrm{~min}$ and then instantly frozen with liquid nitrogen and freeze-dried. The freeze-dried powder sample was calcined in air for one hour at $550{ }^{\circ} \mathrm{C}$, with a heating rate of $5{ }^{\circ} \mathrm{C}$ per minute from room temperature to $550^{\circ} \mathrm{C}$.

Synchronous energy-dispersive in situ XAS and mass spectrometry measurements were performed at beamline ID24 at the European Synchrotron Radiation Facility in Grenoble, France. A modified Spectratech reaction cell $^{22}$ was used to which gas was admitted using air-actuated high-speed 4-way gas valves (Valco, VICI) to maintain constant flow when switching between gas compositions. For $\mathrm{Pd} / \mathrm{Al}_{2} \mathrm{O}_{3}$ a sample cup with diameter $5 \mathrm{~mm}$ and depth $2.5 \mathrm{~mm}$ was used and it was loaded with $43 \mathrm{mg}$ of catalyst powder. For $\mathrm{Pd} / \mathrm{CeO}_{2}$ a smaller sample cup with diameter $2.5 \mathrm{~mm}$ and depth $2.5 \mathrm{~mm}$ was used due to the higher attenuation of X-rays in ceria compared to alumina. The sample cup was loaded with $15 \mathrm{mg}$ catalyst powder. The temperature in the reaction cell was controlled by a thermocouple inserted in the top of the catalyst bed. ED-XAS was 
measured using an Si[311] polychromator in Bragg configuration and a FReLoN detector ${ }^{23}$ to monitor the $\mathrm{Pd}$ K-edge at $24350 \mathrm{eV}$. The energy resolution can be estimated from $\Delta E / E$ which is about $1 \times 10^{-4}$ and gives an energy resolution of $2.5 \mathrm{eV}$. The X-ray spot size on the sample was about $150 \mu \mathrm{m}$ (FWHM) in the horizontal direction and in the vertical direction the beam was defocused from a standard $100 \mu \mathrm{m}$ to about $300 \mu \mathrm{m}$. This method has been found to give good results for measurements of spatially nonuniform samples at ID24 ${ }^{24}$. The sampling time for ED-XAS data was $190 \mathrm{~ms}$ for $\mathbf{P d} / \mathbf{A l}_{\mathbf{2}} \mathbf{O}_{\mathbf{3}}$ and $1040 \mathrm{~ms}$ for $\mathrm{Pd} / \mathrm{CeO}_{2}$. A palladium foil (Goodfellow, $99.99 \%$ purity) was used for energy calibration of the obtained ED-XAS spectra and reference spectra were also recorded for PdO (Alfa Aeasar, 99.9\% purity). The outlet stream from the reactor was analyzed by mass spectrometry (Pfeiffer, Prisma) following the $m / z 2\left(\mathrm{H}_{2}\right), 4(\mathrm{He}), 15\left(\mathrm{CH}_{4}\right), 28(\mathrm{CO}), 32\left(\mathrm{O}_{2}\right)$, and $44\left(\mathrm{CO}_{2}\right)$. Energy calibration and normalization of the XAS spectra were performed with the PrestoPronto software ${ }^{25}$. For the EXAFS analysis all processing steps, including energy calibration and normalization, were performed with the Larch software ${ }^{26}$ using scattering paths calculated with FEFF6L ${ }^{27}$.

Oxygen pulse-response experiments were performed at 400, 350, and $300{ }^{\circ} \mathrm{C}$ for $\mathrm{Pd} / \mathrm{Al}_{2} \mathrm{O}_{3}$ and at 350,300 , and $250^{\circ} \mathrm{C}$ for $\mathrm{Pd} / \mathrm{CeO}_{2}$. Prior to the experiment, the sample was treated with $1.5 \% \mathrm{O}_{2}$ and then exposed to $0.8 \% \mathrm{H}_{2}$ at $400{ }^{\circ} \mathrm{C}$ for $20 \mathrm{~min}$. The temperature was lowered to the temperature set for the experiment and the pulse-response experiment was started by switching to a lean gas composition of $1.5 \% \mathrm{O}_{2} / 0.1 \% \mathrm{CH}_{4}$ which was held for 5 min. The introduction of the first lean period triggered the recording of XAS spectra. The feed gas was then switched to a rich gas composition of $0.1 \% \mathrm{CH}_{4}$ which was held for 5 minutes. This 10 minute period with lean and rich feed gas compositions was then repeated twice to give a total duration of the experiment of $30 \mathrm{~min}$. Helium was used as the carrier gas and the total flow was kept constant at $100 \mathrm{~mL} \mathrm{~min}{ }^{-1}$ for both the $\mathrm{Pd} / \mathrm{Al}_{2} \mathrm{O}_{3}$ and $\mathrm{Pd} / \mathrm{CeO}_{2}$ samples. For $\mathrm{Pd} / \mathrm{CeO}_{2}$ a lower flow is needed to achive the same residence time as the $\mathrm{Pd} / \mathrm{Al}_{2} \mathrm{O}_{3}$ sample, due to the smaller sample volume. This 
was, however, not possible to achieve without changing the concentration of the reactants and therefore the same total flow and feed compositions were used in order to analyze the reaction kinetics in the same concentration regime for both samples. The different space velocities, GHSV $=120000 \mathrm{~h}^{-1}$ for $\mathbf{P d} / \mathrm{Al}_{\mathbf{2}} \mathrm{O}_{\mathbf{3}}$ and $\mathrm{GHSV}=490000 \mathrm{~h}^{-1}$ for $\mathbf{P d} / \mathrm{CeO}_{2}$, and the different amounts of catalyst used make it not possible to directly quantitatively compare the methane outlet concentrations from $\mathrm{Pd} / \mathrm{Al}_{2} \mathrm{O}_{3}$ and $\mathrm{Pd} / \mathrm{CeO}_{2}$ in the present experiment.

\section{Results and Discussion}

The stable phase of palladium in air at temperatures lower than $790{ }^{\circ} \mathrm{C}$ is $\mathrm{PdO}^{28}$, whilst at higher temperatures PdO decomposes to metallic Pd. Due to this, many previous studies of methane oxidation over palladium catalysts have accessed the metallic Pd state in the high conversion region at high temperature ${ }^{3}$. The focus in the present study is on methane oxidation at low temperatures. By performing in situ X-ray absorption spectroscopy measurements during oxygen pulse-response experiments where the reaction conditions are periodically switched from net-reducing to net-oxidizing, we correlate the changes in chemical state of the supported palladium nanoparticles with changes in activity and selectivity for methane oxidation. It can be worth to mention that at low temperatures (lower than $450{ }^{\circ} \mathrm{C}$ ) water has been reported to inhibit methane oxidation over $\mathrm{PdO}$ catalysts ${ }^{29,30}$. In the present study, however, water is only produced as a reaction product, which is expected to have a minor effect on the methane oxidation kinetics as compared to addition of water in the feed.

Figure 1 shows the evolution of the XAFS spectra for $\mathrm{Pd} / \mathrm{Al}_{2} \mathrm{O}_{3}$ at $400{ }^{\circ} \mathrm{C}$ during the rich-lean cycling experiment. Prior to the experiment, the catalyst is reduced in $\mathrm{H}_{2}$ and when the first lean period is introduced the recording of the XAFS spectra starts. The left panel of Figure 1 shows XAFS spectra recorded at the end of the lean and rich periods, while the right panel shows the color coded intensities of the XAFS spectra together with 
the outlet concentrations of oxygen and methane as functions of time during the experiment. The XAFS spectra in the left panel are clearly different when they are recorded at the end of a rich period compared to the end of lean period, and the spectra recorded at different rich or lean periods are very similar to one another. The evolution of spectral features as a function of time can be seen in the color coded intensity plot in the right panel and these can be compared to the outlet concentrations plotted below. The outlet concentration of methane correlates strongly to the spectral change observed when the feed gas is cycled between rich and lean composition.
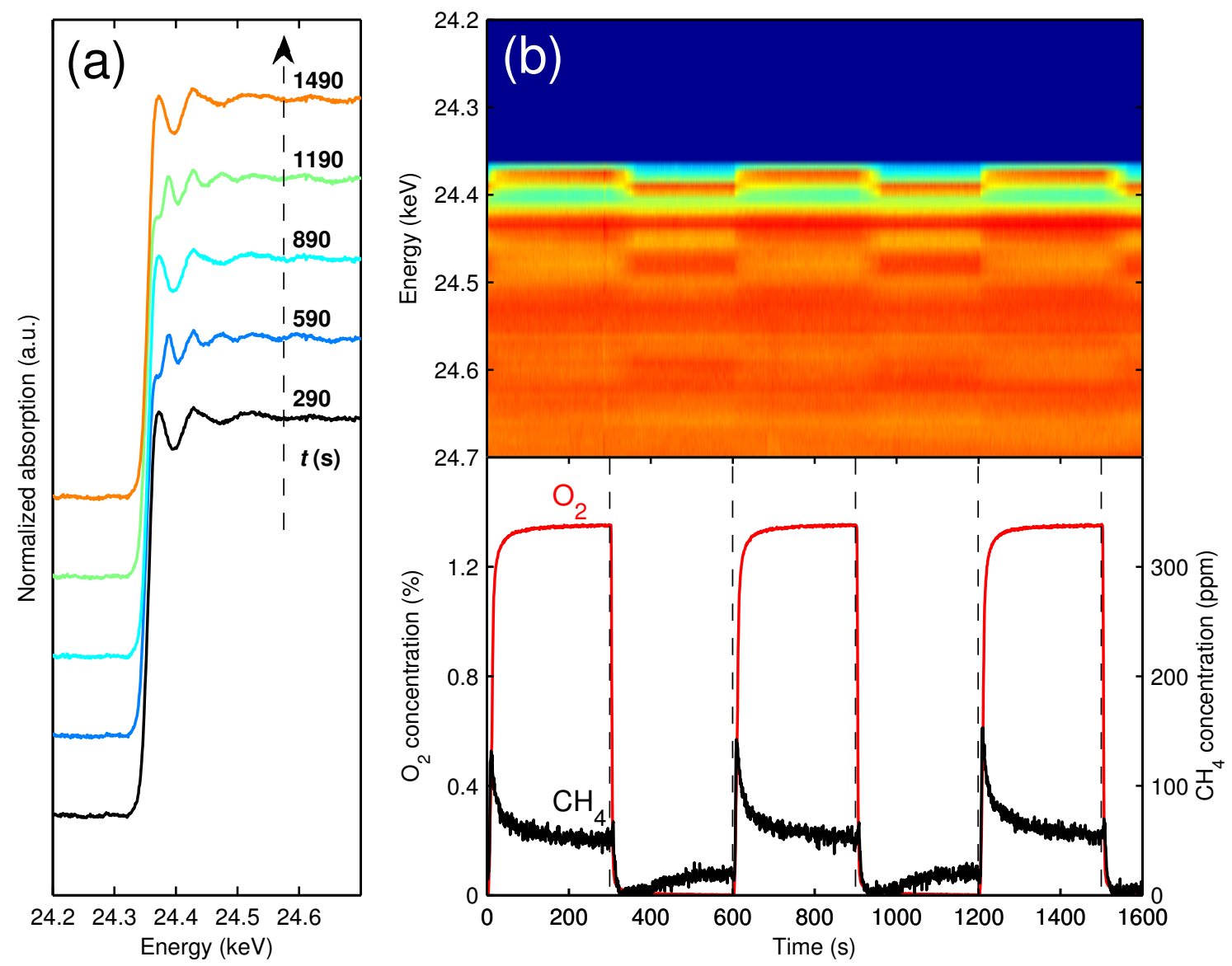

Figure 1: XAFS spectra recorded during consecutive 300 s lean $\left(1.5 \% \mathrm{O}_{2}\right.$ and $\left.0.1 \% \mathrm{CH}_{4}\right)$ and rich $\left(0.1 \% \mathrm{CH}_{4}\right)$ periods over $\mathrm{Pd} / \mathrm{Al}_{2} \mathrm{O}_{3}$ at $40{ }^{\circ} \mathrm{C}$. (a) XAFS spectra recorded at the end of the rich and lean periods. (b) Color coded intensities of XAFS spectra (blue: low intensity and red: high intensity) and outlet concentrations of oxygen and methane as a function of time recorded during the lean-rich cycling experiment.

The spectra recorded during the end of the rich and lean periods are similar to the spec- 
tra of $\mathrm{Pd}$ foil and $\mathrm{PdO}$ powder, respectively, which are depicted in Figure 2. To analyze the features of the time-resolved spectra we perform the demodulation described by eq 1 to produce the demodulated spectra are shown in Figure 2. These spectra contain only the signals that change during the experiment and static signals like the absorption edge and the background disappear during the demodulation. A similar result can be obtained by subtracting one XAFS spectrum from another, producing a difference spectrum. The difference spectrum between the XAFS spectra for $\mathrm{Pd}$ foil and $\mathrm{PdO}$ powder is shown in Figure 2 and it has a second-derivative profile like the one found in the demodulated spectra. The demodulated spectra are difference spectra, however, the signal-to-noise ratio is much improved due to the phase sensitive detection technique. We use here the difference spectrum between $\mathrm{Pd}$ foil and $\mathrm{PdO}$ as a reference spectrum for comparison with the demodulated spectra, to establish a connection between the changes occurring in the XAFS spectra and the reference states of metallic $\mathrm{Pd}$ and $\mathrm{PdO}$, respectively. The difference spectrum corresponds to the situation where palladium undergoes a straightforward oxidation-reduction process. Comparing the difference spectrum with the demodulated spectra there is a high degree of correspondence which shows that the changes in the XAFS spectra as a function of time is caused by an oxidation-reduction process of the palladium nanoparticles. In the present experiments the XANES region of the spectra changes considerably during the transition from the reduced state to the oxidized state (Figure 1). Thus, the present analysis is not dependent on the improved signal-to-noise ratio as achieved by the demodulation procedure. In principle phase sensitive detection can also help to differentiate species appearing with different kinetics ${ }^{20}$, however, in the present experiment the spectral changes are attributed to interconversion between two states.

In the demodulated spectra the most intense feature is the peak corresponding to the white line at $24.37 \mathrm{keV}$. Thus, we use the white line intensity to follow oxidation and reduction of $\mathrm{Pd}$. Figure 3 and 4 show the outlet concentrations measured with mass spectrometry 


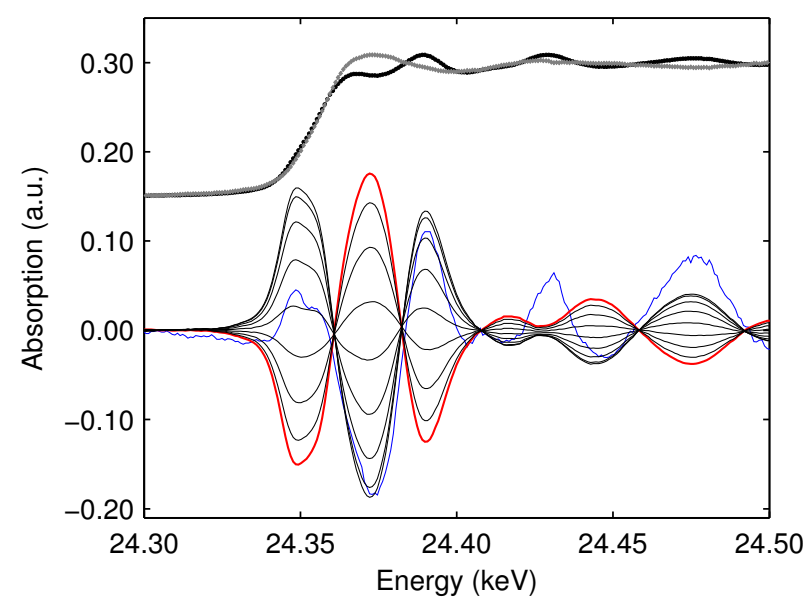

Figure 2: Demodulated spectra obtained from $\mathrm{Pd} / \mathrm{Al}_{2} \mathrm{O}_{3}$ at $400^{\circ} \mathrm{C}\left(\phi_{k}^{P S D}=0-160^{\circ}\right)$ together with scaled spectra of $\mathrm{Pd}$ foil and $\mathrm{PdO}$ powder. The red spectrum corresponds to $\phi_{k}^{P S D}=0^{\circ}$ and blue spectrum is the scaled difference spectrum $\mathrm{Pd}_{\text {foil }}-\mathrm{PdO}$.

together with the white line intensity during the pulse-response experiments for $\mathrm{Pd} / \mathrm{Al}_{2} \mathrm{O}_{3}$ and $\mathrm{Pd} / \mathrm{CeO}_{2}$, respectively, at different temperatures. The temporal response of the methane outlet concentration is qualitatively similar for $\mathrm{Pd} / \mathrm{Al}_{2} \mathrm{O}_{3}$ and $\mathrm{Pd} / \mathrm{CeO}_{2}$ during the first part of the lean period. When the lean period is introduced, the outlet concentration of $\mathrm{CH}_{4}$ decreases rapidly in all measurements except for $\mathrm{Pd} / \mathrm{Al}_{2} \mathrm{O}_{3}$ at $400^{\circ} \mathrm{C}$ and $\mathrm{Pd} / \mathrm{CeO}_{2}$ at $250^{\circ} \mathrm{C}$. Following the initial decrease the $\mathrm{CH}_{4}$ concentration increases again, then drops, and later appears to approach steady state for the duration of the lean period. The initial decrease in methane outlet concentration when oxygen is introduced is most likely caused by an increase in methane oxidation due to the increased availability of oxygen. Oxidation of the Pd nanoparticles start when oxygen is introduced, as indicated by the rapidly increasing white line intensity. The mechanism for oxidation of $\mathrm{Pd}$ nanoparticles have been studied with high-pressure X-ray photoelectron spectroscopy (XPS) ${ }^{31}$ where it was found that adsorbed oxygen would initially create a surface oxide before larger domains of palladium oxide start growing. The growth of a bulk oxide from the surface oxide has been associated with a strong kinetic hindrance in the oxidation of the $\operatorname{Pd}(100)$ surface $^{32}$. For methane oxidation the $\mathrm{PdO}(101)$ facet has been identified as highly activity when a sufficiently thick film of oxide had been grown on $\operatorname{Pd}(100)^{16}$. On the basis of DFT calculations under-coordinated Pd sites 
in $\mathrm{PdO}(101)$ have been identified as having a low energy barrier for hydrogen abstraction from $\mathrm{CH}_{4}$ when an oxygen atom is present directly below the adsorbing $\mathrm{Pd}$ atom ${ }^{33}$, as is found in a two-layer $\mathrm{PdO}(101)$ film. These observations can be connected to the methane conversion observed in the present experiments; after the initial increase in methane conversion the conversion decreases which indicates that the catalyst becomes less active during the initial phase of the oxidation when the surface is covered by chemisorbed oxygen or a surface oxide. When the oxidation has proceeded so that a sufficiently thick oxide is formed the activity of the catalyst increases with $\mathrm{PdO}$ being the active phase. TEM images of $\mathrm{PdO}$ supported on $\theta-\mathrm{Al}_{2} \mathrm{O}_{3}$ indicate that oxidation of $\mathrm{Pd}$ to $\mathrm{PdO}$ results in extensive surface roughening ${ }^{34}$. It is not unlikely in our experiments that the deep oxidation of the $\mathrm{Pd}$ nanoparticles results in volumetric expansion and surface roughening which creates under-coordinated PdO sites which are highly active for methane dissociation.

For the ceria supported catalyst a reduction in methane conversion can also be observed initially after oxygen has been introduced, but it is much less pronounced compared to the corresponding experiment with $\mathrm{Pd} / \mathrm{Al}_{2} \mathrm{O}_{3}$. The introduction of oxygen leads to a rapid increase of the white line intensity, corresponding to a shift towards an oxidized state of palladium according to the phase sensitive detection analysis. For $\mathrm{Pd} / \mathrm{Al}_{2} \mathrm{O}_{3}$ the increase in the white line intensity is linear for the first few seconds after introducing oxygen and after that the rate of increase declines. The profiles are similar at 400 and $350^{\circ} \mathrm{C}$, but at $300^{\circ} \mathrm{C}$ the increase in the white line intensity during the lean period is smaller than at higher temperatures. For $\mathrm{Pd} / \mathrm{CeO}_{2}$ the increase in the white line intensity at 350 and $300^{\circ} \mathrm{C}$ is very different compared to $\mathrm{Pd} / \mathrm{Al}_{2} \mathrm{O}_{3}$, here the white line intensity increases almost linearly until the maximum value is reached. At $250{ }^{\circ} \mathrm{C}$ the increase in the white line intensity is more similar to that found for $\mathrm{Pd} / \mathrm{Al}_{2} \mathrm{O}_{3}$. Since $\mathrm{Pd}$ is oxidized more rapidly when supported on ceria compared to alumina the reduction of the conversion observed when oxygen is introduced is minor on $\mathrm{Pd} / \mathrm{CeO}_{2}$ compared to $\mathrm{Pd} / \mathrm{Al}_{2} \mathrm{O}_{3}$. On $\mathrm{Pd} / \mathrm{CeO}_{2}$ a stable oxide can be established quickly so that chemisorbed oxygen on the Pd 

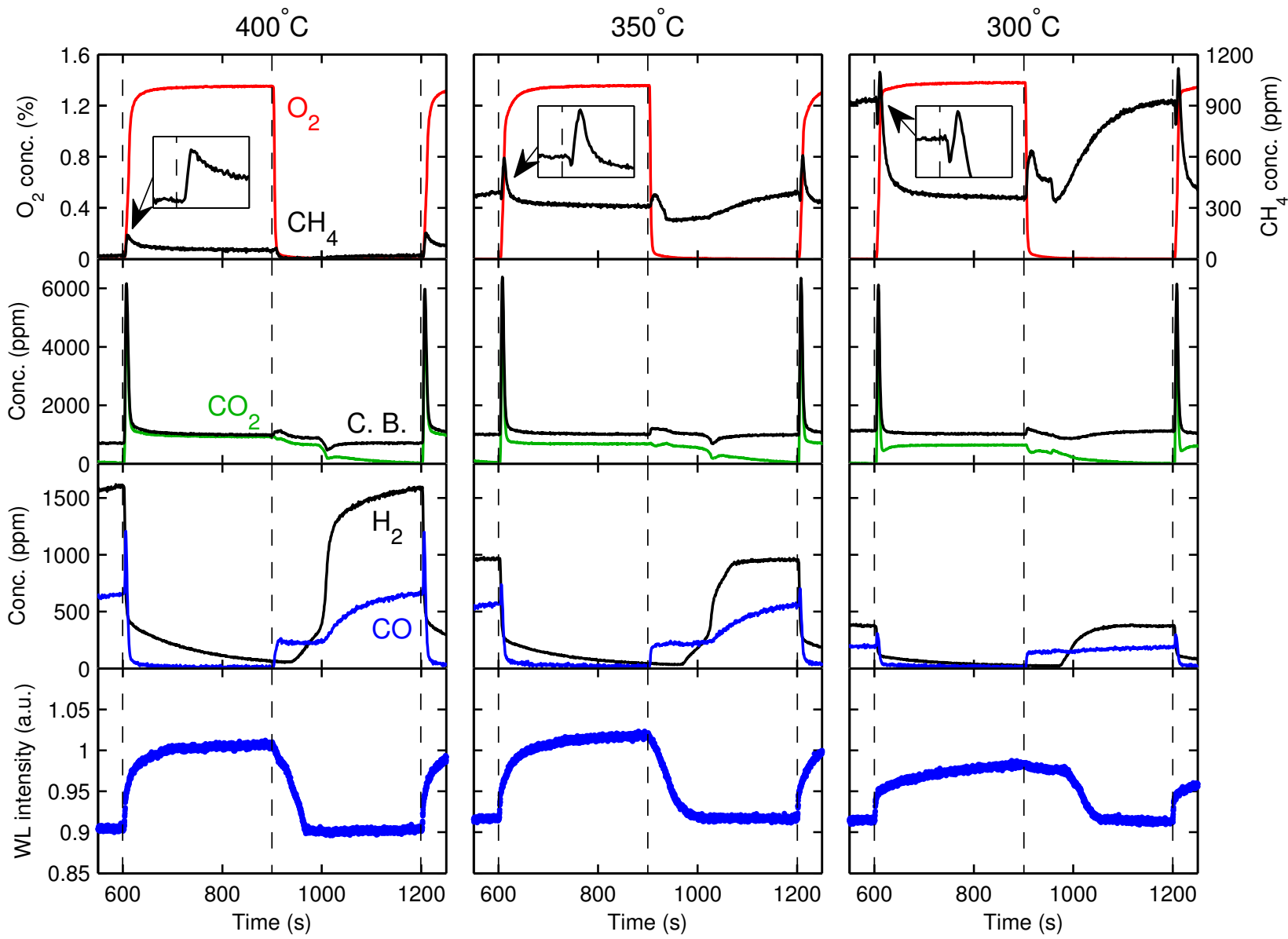

Figure 3: Oxidation of $0.1 \% \mathrm{CH}_{4}$ over $\mathrm{Pd} / \mathrm{Al}_{2} \mathrm{O}_{3}$ where $1.5 \% \mathrm{O}_{2}$ is introduced for one period. The top panel shows the outlet concentration of $\mathrm{O}_{2}$ and $\mathrm{CH}_{4}$, the second panel shows the outlet concentration of $\mathrm{CO}_{2}$ and the carbon balance, defined as $C_{\mathrm{CH}_{4}}+C_{\mathrm{CO}}+C_{\mathrm{CO}_{2}}$. The third panel shows the outlet concentration of $\mathrm{H}_{2}$ and $\mathrm{CO}$, the bottommost panel shows the XAFS white line intensity at $24372 \mathrm{eV}$. 

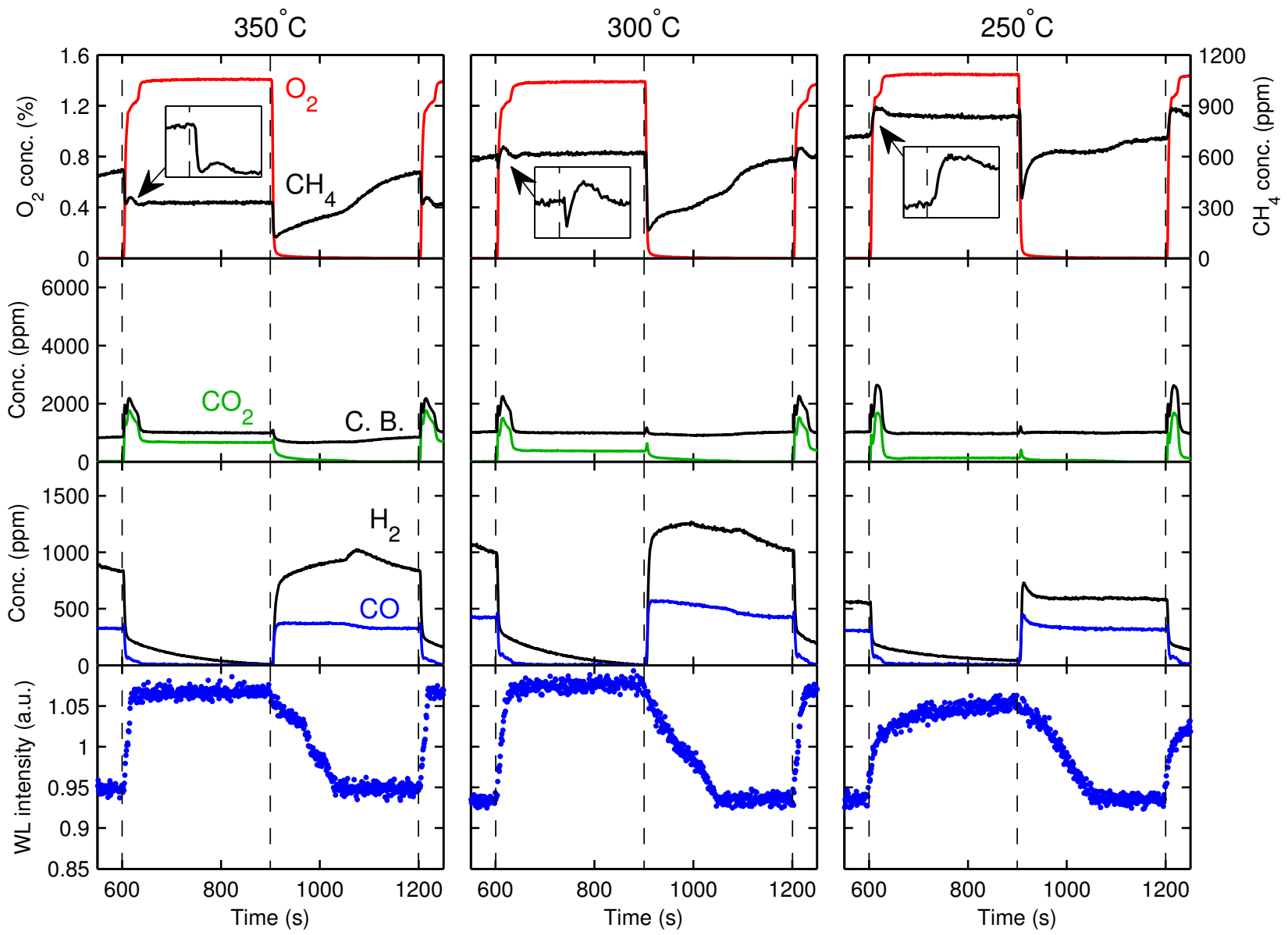

Figure 4: Oxidation of $0.1 \% \mathrm{CH}_{4}$ over $\mathrm{Pd} / \mathrm{CeO}_{2}$ where $1.5 \% \mathrm{O}_{2}$ is introduced for one period. The top panel shows the outlet concentration of $\mathrm{O}_{2}$ and $\mathrm{CH}_{4}$, the second panel shows the outlet concentration of $\mathrm{CO}_{2}$ and the carbon balance, defined as $C_{\mathrm{CH}_{4}}+C_{\mathrm{CO}}+C_{\mathrm{CO}_{2}}$. The third panel shows the outlet concentration of $\mathrm{H}_{2}$ and $\mathrm{CO}$, the bottommost panel shows the XAFS white line intensity at $24372 \mathrm{eV}$. 
surface will have less impact on the conversion. The more readily oxidation of Pd when supported on ceria compared to alumina has also been observed previously in the reformation of $\mathrm{PdO}$ upon cooling after decomposition at high temperature ${ }^{35}$. In the study by Farrauto et al. ${ }^{35}$ it was found that the hysteresis between heating and cooling for this process is significantly reduced for $\mathrm{Pd} / \mathrm{CeO}_{2}$ compared to $\mathrm{Pd} / \mathrm{Al}_{2} \mathrm{O}_{3}$. The difference between $\mathrm{Pd} / \mathrm{Al}_{2} \mathrm{O}_{3}$ and $\mathrm{Pd} / \mathrm{CeO}_{2}$ in the present study can be explained by the oxygen storage capability of ceria and oxygen transport to the Pd particles which enhance the oxidation process. The difference in our measurements between $\mathrm{Pd} / \mathrm{CeO}_{2}$ at $250{ }^{\circ} \mathrm{C}$ and at higher temperatures indicates that the oxygen transport from the support to Pd becomes slow at lower temperatures. Palladium interacts strongly with the ceria support and the morphology and oxidation state of Pd nanoparticles can vary depending on catalyst synthesis and pretreatment methods. High activity for methane oxidation in $\mathrm{Pd} / \mathrm{CeO}_{2}$ catalyst has been linked to cationic $\mathrm{Pd}$ species in close contact with the support ${ }^{36}$ and species with $\mathrm{Pd}-\mathrm{O}-\mathrm{Ce}$ linkages ${ }^{37}$.

When oxygen is introduced there is a sharp peak in the outlet concentration of $\mathrm{CO}_{2}$ which likely is the result of the oxidation of carbonaceous species adsorbed on the surface during the rich period. This process appears to have a longer duration over $\mathrm{Pd} / \mathrm{CeO}_{2}$ compared to $\mathrm{Pd} / \mathrm{Al}_{2} \mathrm{O}_{3}$ and following this peak the the outlet $\mathrm{CO}_{2}$ concentration holds steady for both catalysts during the remainder of the lean period. Also, the outlet concentration of CO increases slightly at the start of the lean period. Comparing the outlet oxygen concentration between $\mathrm{Pd} / \mathrm{Al}_{2} \mathrm{O}_{3}$ and $\mathrm{Pd} / \mathrm{CeO}_{2}$ when oxygen is introduced there is a clear difference between the two samples. For the ceria supported catalyst there is a shoulder on the rising edge while for the alumina supported sample there is a smooth increase in oxygen concentration when oxygen is introduced. This difference is likely connected to the differences in $\mathrm{CO}_{2}$ production observed at this time.

At the start of the rich period there is a difference in behavior between the alumina and ceria supported catalysts. The outlet methane concentration for $\mathrm{Pd} / \mathrm{Al}_{2} \mathrm{O}_{3}$ has a peak when the oxygen supply is switched off at 350 and $300{ }^{\circ} \mathrm{C}$. The peak at $300{ }^{\circ} \mathrm{C}$ is 
much stronger than that at $350{ }^{\circ} \mathrm{C}$ and it has a shoulder on the falling edge, but at $400{ }^{\circ} \mathrm{C}$ this peak is not seen. This increase in concentration is likely caused by the rapidly decreasing concentration of oxygen in the gas phase and the depletion of oxygen at $\mathrm{PdO}$ sites which are active for methane oxidation during the lean period. However, when the reduction of the catalyst has started, as indicated by the decreasing white line intensity, the conversion of methane increases when metallic Pd sites become active for methane dissociation. After some time in the rich period oxygen becomes the limiting reactant and thus partial oxidation of methane increases as indicated by the increasing concentrations of $\mathrm{CO}$ and $\mathrm{H}_{2}$, and the decreasing concentration of $\mathrm{CO}_{2}$.

For $\mathrm{Pd} / \mathrm{CeO}_{2}$ the outlet methane concentration decreases rapidly when oxygen is removed for the feed, although at $250{ }^{\circ} \mathrm{C}$ a small peak can be seen before the concentration declines. Simultaneously, the concentrations of $\mathrm{H}_{2}$ and CO increase which is different compared to $\mathrm{Pd} / \mathrm{Al}_{2} \mathrm{O}_{3}$ where there is a delay between the removal of oxygen from the feed gas and the increasing outlet concentrations of $\mathrm{H}_{2}$ and $\mathrm{CO}$. It is possible that this difference is connected to reduction of the ceria support which leads to increased oxygen mobility. Bozo et al. have reported that in situ reduction of a $\mathrm{Pd} / \mathrm{CrZrO}_{2}$ catalyst caused a strong increase in methane conversion ${ }^{18}$, this was attributed to the creation of oxygen vacancies in the support improving the activity through electron transfer to the metal component and increased lattice oxygen mobility ${ }^{18}$. Haneda et al. reported high activity for a $\mathrm{Pd} / \mathrm{CeO}_{2-\mathrm{x}} / \mathrm{Al}_{2} \mathrm{O}_{3}$ catalyst with a nonstochiometric cerium oxide support and this was attributed to a fast diffusion rate of oxygen in the $\mathrm{CeO}_{2-\mathrm{x}}$ lattice and reverse spillover of oxygen to $\mathrm{Pd}$. Reverse spillover could be the cause of the increasing methane conversion for the $\mathrm{Pd} / \mathrm{CeO}_{2}$ catalyst in the beginning of the rich period since the increase in conversion appears not to be the result from a change in the oxidation state. The increasing outlet concentrations of $\mathrm{H}_{2}$ and CO suggest that partial oxidation is dominant at this time. 
Based on the EXAFS analysis presented below we suggest that $\mathrm{Pd} / \mathrm{Al}_{2} \mathrm{O}_{3}$ at 400 and $350{ }^{\circ} \mathrm{C}$ during the lean period is oxidized from a metallic state to a bulk oxidized state. At $300{ }^{\circ} \mathrm{C}$, however, both EXAFS and the white line intensity indicate that oxidation is far from complete. Initially during the rich period at $300{ }^{\circ} \mathrm{C}$ the white line intensity decreases quite slowly which indicates a limited reduction of the Pd nanoparticles, possibly only the removal of oxygen adsorbed to $\mathrm{Pd}$. After some time in the rich period the rate of reduction increases until $\mathrm{Pd}$ is almost completely reduced. The white line intensity decreases more rapidly for $\mathrm{Pd} / \mathrm{Al}_{2} \mathrm{O}_{3}$ than for $\mathrm{Pd} / \mathrm{CeO}_{2}$ when the oxygen supply is switched off which indicates that the reduction of $\mathrm{Pd}$ in $\mathrm{Pd} / \mathrm{Al}_{2} \mathrm{O}_{3}$ is more rapid. Ceria is known to stabilize metals in an oxidized state due to the high redox potential of the $\mathrm{Ce}^{4+} / \mathrm{Ce}^{3+}$ couple $(1.61 \mathrm{eV})$ compared to e.g. $\mathrm{Pd}^{2+} / \mathrm{Pd}^{0} 18$.

Fouladvand et al. also found a lower conversion at the start of the rich period during rich-lean cycling experiments with these types of catalyst systems ${ }^{17}$. This was ascribed to palladium in intermediate oxidation states being less active for methane oxidation, however, the present XANES data indicate high activity when the catalyst is in between the oxidized and reduced state. In the present study we interpret the lower conversion to be more of an effect of the surface coverages rather than the overall oxidation state of the Pd nanoparticles. Thevenin et al. ${ }^{38}$ have argued based on XPS studies, and also Kinnunen et al. ${ }^{39}$ based on $\mathrm{NH}_{3}$ desorption, that the simultaneous presence of reduced and oxidized $\mathrm{Pd}$ is necessary for high activity for methane oxidation. For $\mathrm{Pd} / \mathrm{Al}_{2} \mathrm{O}_{3}$ the highest conversion is observed at the beginning of the rich period during the reduction oxidized palladium to metallic palladium. This can be caused by a high activity for methane oxidation over reduced Pd sites or by high activity over mixed $\mathrm{Pd} / \mathrm{PdO}$ sites. It is difficult to compare the conversion in the beginning of the rich period with the conversion in the later parts of the rich period, when palladium is fully reduced, since oxygen is a limiting reactant.

To gain more information about the local structure surrounding the palladium atoms a 

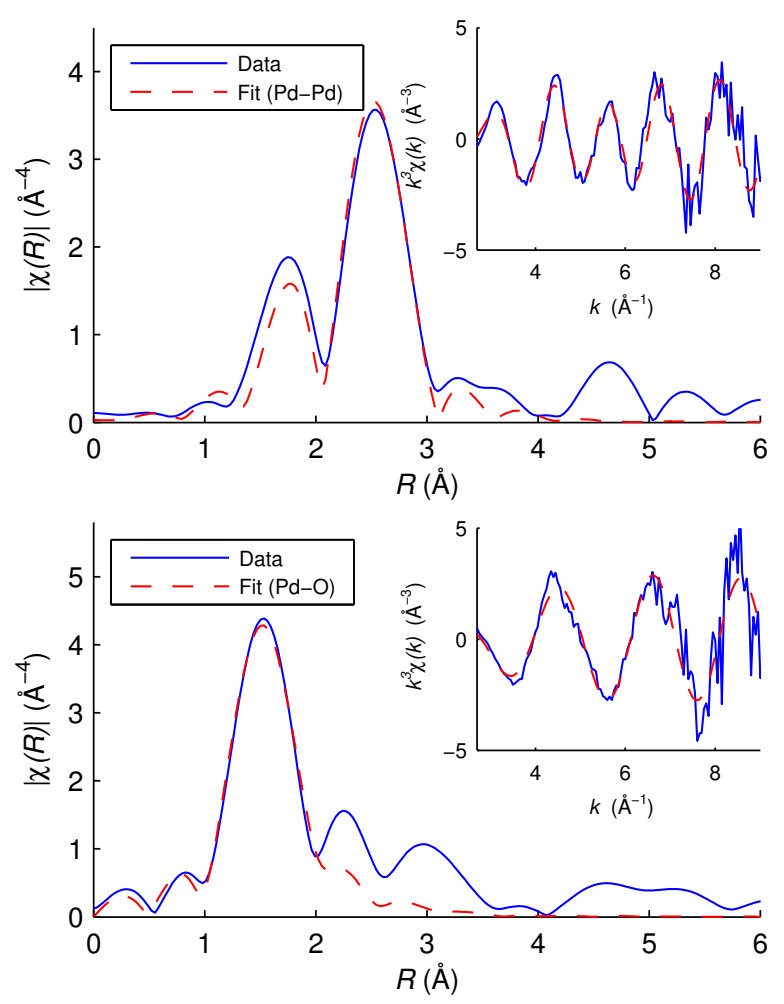

Figure 5: Fourier transformed EXAFS spectra from $\mathrm{Pd} / \mathrm{Al}_{2} \mathrm{O}_{3}$ at $350{ }^{\circ} \mathrm{C}$. 40 spectra were averaged and analyzed with a $k$ range from $2.7 \AA^{-1}$ to $9 \AA^{-1}$. (top) Spectra recorded at the end of a rich period (1182-1190s) fitted to the shortest Pd-Pd scattering path in bulk Pd, fit range is 1.2 to $3.0 \AA$. (bottom) Spectra recorded at the end of a lean period $(882-890 \mathrm{~s})$ fitted to the shortest $\mathrm{Pd}-\mathrm{O}$ scattering path in bulk $\mathrm{PdO}$, fit range is 1.0 to $2.0 \AA$.

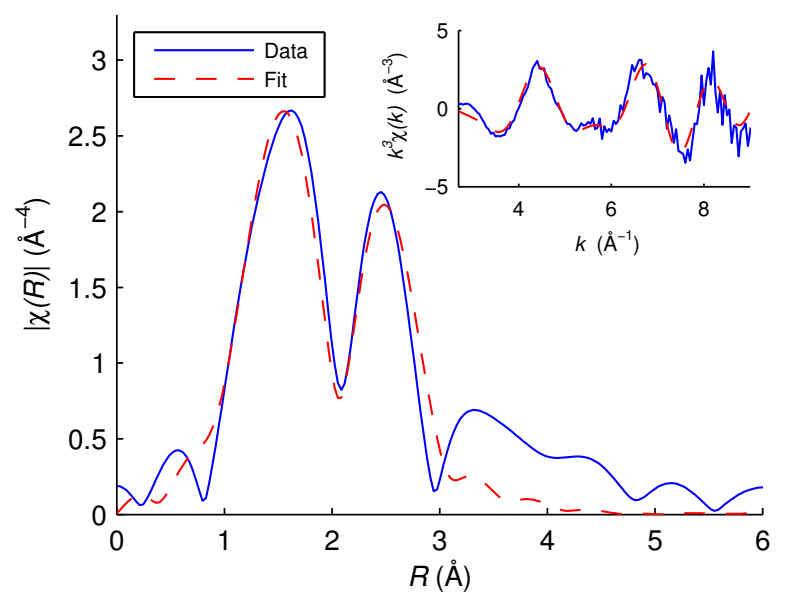

Figure 6: Fourier transformed EXAFS spectrum from $\mathrm{Pd} / \mathrm{Al}_{2} \mathrm{O}_{3}$ at $300^{\circ} \mathrm{C} .40$ spectra were averaged and analyzed with a $k$ range from $2.7 \AA^{-1}$ to $9 \AA^{-1}$. The spectra were recorded at the end of the lean period 882-890s and fitted to a $\mathrm{Pd}-\mathrm{O}$ and $\mathrm{Pd}-\mathrm{Pd}$ scattering path with fit range $1.0 \AA$ to $3.0 \AA$. 
conventional EXAFS analysis was performed for the $\mathrm{Pd} / \mathrm{Al}_{2} \mathrm{O}_{3}$ catalyst, the measurements for $\mathrm{Pd} / \mathrm{CeO}_{2}$ had a much shorter post edge region not suitable for EXAFS analysis. The full XAFS spectra are provided in Figures S1, S2, and S3 in Supporting Information. Figure 5 shows the Fourier transformed EXAFS spectra recorded during the end of the rich and lean periods at $350{ }^{\circ} \mathrm{C}$. The spectra recorded during the rich period feature at double peak at 1.7 and $2.5 \AA$ which is attributed to a single Pd neighbor. This assignment has also been made by Reimann et al. ${ }^{40}$ based on the rationalization that: (i) the amplitude ratio of the two peaks does not change with different $k$-weights as would be expected for contributions of lighter backscattering atoms, (ii) the two peaks can be fitted with a good result to a path of the first $\mathrm{Pd}$ shell of bulk $\mathrm{Pd}$, (iii) the double peak feature is found also in EXAFS analysis of a pure Pd foil if the same $k$-range is used for Fourier transformation. The fit using a path for the first Pd shell in bulk Pd yields a bond distance of 2.70(1) $\AA$ for our data, which is close to the first shell $\mathrm{Pd}-\mathrm{Pd}$ distance in bulk palladium at $2.75 \AA$. Comparing the spectra recorded during the lean period with the spectra recorded during the rich period it can be seen that the main peak has moved to a much shorter distance. This peak was fitted to a $\mathrm{Pd}-\mathrm{O}$ scattering path with a bond distance of 2.02(1) $\AA$, which can be compared to 2.02 for the shortest $\mathrm{Pd}-\mathrm{O}$ distance in bulk $\mathrm{PdO}^{41}$. The EXAFS analysis shows that during the lean period the $\mathrm{Pd}$ nanoparticles are in an oxidized state similar to bulk $\mathrm{PdO}$ but when the switch is made to the rich period the $\mathrm{PdO}$ phase is reduced to a state which is closer to metallic $\mathrm{Pd}$. For $\mathrm{Pd} / \mathrm{Al}_{2} \mathrm{O}_{3}$ at $300^{\circ} \mathrm{C}$ the oxidation of $\mathrm{Pd}$ during the lean periods is not as complete as is found at higher temperatures. Figure 6 shows the Fourier transformed EXAFS spectra at $300^{\circ} \mathrm{C}$ recorded at the same time as the EXAFS spectra from the lean period at $350^{\circ} \mathrm{C}$ shown in Figure 5. Here we clearly see a much stronger contribution from Pd-Pd scattering compared to the higher temperature which indicates that Pd is not fully oxidized. The EXAFS is fitted to a Pd-O scattering path and a $\mathrm{Pd}-\mathrm{Pd}$ scattering path which gives a Pd-O distance of 2.00(2) and Pd-Pd distance 2.71(2) To show how the spectra changes between the rich and lean periods the time evolution of the Fourier transformed 
EXAFS spectrum is shown in Figure 7. When the switch is made between the rich to lean periods at $600 \mathrm{~s}$ the double peak from $\mathrm{Pd}-\mathrm{Pd}$ scattering diminishes and simultaneously the $\mathrm{Pd}-\mathrm{O}$ scattering peak increases in intensity. When the switch is made back to a rich period at $900 \mathrm{~s}$ the process is reversed. The increase in intensity of the $\mathrm{Pd}-\mathrm{O}$ scattering peak at the rich-lean switch is very similar to the increase in white line intensity seen in Figure 3 showing that both XANES and EXAFS give the same description of the oxidation process.

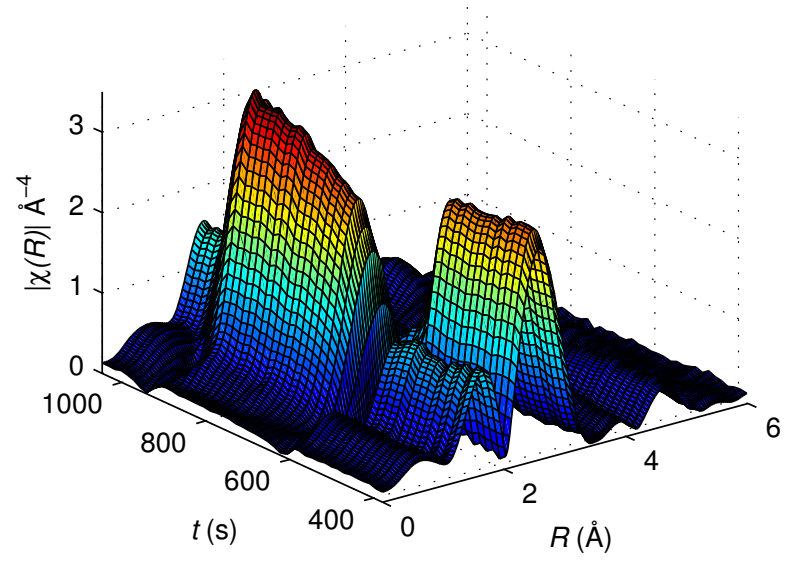

Figure 7: Fourier transformed EXAFS spectra as a function of time for $\mathrm{Pd} / \mathrm{Al}_{2} \mathrm{O}_{3}$ at $350{ }^{\circ} \mathrm{C}$ during consecutive $300 \mathrm{~s}$ lean $\left(1.5 \% \mathrm{O}_{2}\right.$ and $\left.0.1 \% \mathrm{CH}_{4}\right)$ and rich $\left(0.1 \% \mathrm{CH}_{4}\right)$ periods.

Comparing the present results for methane oxidation over palladium catalysts with methane oxidation over platinum catalysts ${ }^{42,43}$ it is found that exposure to net-oxidizing conditions does not have a very detrimental effect on methane conversion. For platinum catalysts periodic cycling has been suggested as a method to reduce the effects of oxygen poisoning and to increase the average conversion. However, for the $\mathrm{Pd} / \mathrm{Al}_{2} \mathrm{O}_{3}$ catalyst in the present study rapid changes in the gas composition was not found to be beneficial for increasing the methane conversion. On the other hand, for the $\mathrm{Pd} / \mathrm{CeO}_{2}$ catalyst the interactions between the active metal phase and the support is found to be beneficial for maintaining high conversion when the gas phase changes and periodic operation can potentially have a positive effect on the overall conversion. 


\section{Conclusions}

Using the phase sensitive detection technique we show that the spectral changes observed in the XAFS spectra during methane oxidation are caused by the oxidation and the reduction of the palladium nanoparticles in the $\mathrm{Pd} / \mathrm{Al}_{2} \mathrm{O}_{3}$ and $\mathrm{Pd} / \mathrm{CeO}_{2}$ samples. The phase sensitive detection analysis adds much clarity and unambiguity when it comes to understanding the observed spectral changes and also provides a clear rationale for using the white line intensity as a measure of the palladium oxidation-reduction process. In combination with the EXAFS analysis this allows us to obtain a clear picture of the oxidation-reduction process of the active palladium phase. The investigations of rich-lean cycling over $\mathrm{Pd} / \mathrm{Al}_{2} \mathrm{O}_{3}$ and $\mathrm{Pd} / \mathrm{CeO}_{2}$ revealed that the major difference between the two support material could be observed at the switches between net-reducing and net-oxidizing feed gas compositions. When a pulse of oxygen was introduced to the system a brief decrease of methane conversion was observed, however, this effect was stronger for $\mathrm{Pd} / \mathrm{Al}_{2} \mathrm{O}_{3}$ than for $\mathrm{Pd} / \mathrm{CeO}_{2}$. The decrease in conversion is attributed to chemisorbed oxygen or surface oxides on the palladium surface and for $\mathrm{Pd} / \mathrm{CeO}_{2}$ the more rapid oxidation of $\mathrm{Pd}$ compared to $\mathrm{Pd} / \mathrm{Al}_{2} \mathrm{O}_{3}$ reduces the effects of this surface composition. Also when oxygen is removed from the feed it is possible to observe a brief decrease in the methane conversion over $\mathrm{Pd} / \mathrm{Al}_{2} \mathrm{O}_{3}$. This is not observed for $\mathrm{Pd} / \mathrm{CeO}_{2}$ where the highest conversion is found just after oxygen has been removed from the feed which is attributed to reverse spillover of oxygen from the support to the active $\mathrm{Pd}$ sites. For $\mathrm{Pd} / \mathrm{Al}_{2} \mathrm{O}_{3}$ the highest conversion during the pulse response experiments is observed in the beginning of the rich periods during the reduction of oxidized palladium to metallic palladium, which indicates that reduced $\mathrm{Pd}$ sites or mixed $\mathrm{Pd} / \mathrm{PdO}$ sites have high activity for methane oxidation. Compared to methane oxidation over platinum catalysts no strong effects of oxygen poisoning was observed for the palladium catalysts in the present study. However, due to the lower conversion observed when the feed gas composition was changed periodic cycling can potentially have a negative effect on the conversion over time. 


\section{Acknowledgement}

Dr. S.J.A. Figueroa is thanked for fruitful discussions concerning the experiments. The authors thank the European Synchrotron Radiation Facility (ESRF), Grenoble, France, for providing the beamtime. This work has been performed within the project "Unravelling catalytically active sites with X-ray absorption spectroscopy", Swedish Research Council (6212011-5009), the Röntgen-Ångström Collaboration "Catalysis on the atomic scale", Swedish Research Council (349-2011-6491), "Time-resolved in situ methods for design of catalytic sites within sustainable chemistry", Swedish Research Council (349-2013-567), and partly

within the Competence Centre for Catalysis, which is hosted by Chalmers University of Technology and financially supported by the Swedish Energy Agency and the member companies AB Volvo, ECAPS AB, Haldor Topsøe A/S, Scania CV AB, Volvo Car Corporation $\mathrm{AB}$ and Wärtsilä Finland $\mathrm{Oy}$.

\section{Supporting Information Available}

EXAFS analysis details. This material is available free of charge via the Internet at http://pubs.acs.org/.

\section{References}

(1) de Gouw, J. A.; Parrish, D. D.; Frost, G. J.; Trainer, M. Earth's Future 2014, 2, 75-82.

(2) Engerer, H.; Horn, M. Energy Policy 2010, 38, 1017-1029.

(3) Ciuparu, D.; Lyubovsky, M. R.; Altman, E.; Pfefferle, L. D.; Datye, A. Catal. Rev. 2002, 44, 593-649.

(4) Han, J.; Zemlyanov, D. Y.; Ribeiro, F. H. Catal. Today 2006, 117, 506-513.

(5) Weiland, P. Appl. Microbiol. Biotechnol. 2010, 85, 849-860. 
(6) Myhre, G.; Shindell, D.; Bréon, F.-M.; Collins, W.; Fuglestvedt, J.; Huang, J.; Koch, D.; Lamarque, J.-F.; Lee, D.; Mendoza, B.; Nakajima, T.; Robock, A.; Stephens, G.; Takemura, T.; Zhang, H. In Climate Change 2013: The Physical Science Basis. Contribution of Working Group I to the Fifth Assessment Report of the Intergovernmental Panel on Climate Change; Stocker, T., Qin, D., Plattner, G.-K., Tignor, M., Allen, S., Boschung, J., Nauels, A., Xia, Y., Bex, V., Midgley, P., Eds.; Cambridge University Press: Cambridge, United Kingdom and New York, NY, USA, 2013; pp 659-740.

(7) Burch, R.; Hayes, M. J. J. Mol. Catal. A: Chem. 1995, 100, 13-33.

(8) Hicks, R. F.; Qi, H.; Young, M. L.; Lee, R. G. J. Catal. 1990, 122, 280-294.

(9) Lyubovsky, M.; Pfefferle, L. Catal. Today 1999, 47, 29-44.

(10) Oh, S. H.; Mitchell, P. J.; Siewert, R. M. J. Catal. 1991, 132, 287-301.

(11) Burch, R.; Loader, P. K.; Urbano, F. J. Catal. Today 1996, 27, 243-248.

(12) McCarty, J. G. Catal. Today 1995, 26, 283-293.

(13) Matam, S. K.; Aguirre, M. H.; Weidenkaff, A.; Ferri, D. J. Phys. Chem. C 2010, 114, 9439-9443.

(14) Yoshida, H.; Nakajima, T.; Yazawa, Y.; Hattori, T. Appl. Catal., B 2007, 71, 70-79.

(15) Burch, R.; Urbano, F. J. Appl. Catal., A 1995, 124, 121-138.

(16) Hellman, A.; Resta, A.; Martin, N. M.; Gustafson, J.; Trinchero, A.; Carlsson, P.-A.; Balmes, O.; Felici, R.; van Rijn, R.; Frenken, J. W. M.; Andersen, J. N.; Lundgren, E.; Grönbeck, H. J. Phys. Chem. Lett. 2012, 3, 678-682.

(17) Fouladvand, S.; Schernich, S.; Libuda, J.; Grönbeck, H.; Pingel, T.; Olsson, E.; Skoglundh, M.; Carlsson, P.-A. Top. Catal. 2013, 56, 410-415.

(18) Bozo, C.; Guilhaume, N.; Herrmann, J.-M. J. Catal. 2001, 203, 393-406. 
(19) Iwasawa, Y. In X-ray Absorption Fine Structure for Catalysts and Surfaces; Iwasawa, Y., Ed.; World Scientific Publishing: Singapore, 1996; p V.

(20) Urakawa, A.; Bürgi, T.; Baiker, A. Chem. Eng. Sci. 2008, 63, 4902-4909.

(21) Ferri, D.; Newton, M. A.; Nachtegaal, M. Top. Catal. 2011, 54, 1070-1078.

(22) Newton, M. A. Top. Catal. 2009, 52, 1410-1424.

(23) Labiche, J.-C.; Mathon, O.; Pascarelli, S.; Newton, M. A.; Ferre, G. G.; Curfs, C.; Vaughan, G.; Homs, A.; Carreiras, D. F. Rev. Sci. Instrum. 2007, 78, 091301.

(24) Newton, M. A. J. Synchrotron Radiat. 2007, 14, 372-381.

(25) Prestipino, C.; Figueroa, S. prestopronto - Software for the analysis of Quick Exafs and Dispersive XAFS data. http://code.google.com/p/prestopronto/ (accessed September 8, 2014).

(26) Newville, M. J. Phys.: Conf. Ser. 2013, 430, 012007.

(27) Rehr, J. J.; Mustre de Leon, J.; Zabinsky, S. I.; Albers, R. C. J. Am. Chem. Soc. 1991, $113,5135-5140$.

(28) Mallika, C.; Sreedharan, O. M.; Gnanamoorthy, J. B. J. Less-Common Met. 1983, 95, $213-220$.

(29) Ciuparu, D.; Katsikis, N.; Pfefferle, L. Appl. Catal., A 2001, 216, 209-215.

(30) Burch, R.; Urbano, F. J.; Loader, P. K. Appl. Catal., A 1995, 123, 173-184.

(31) Westerström, R.; Messing, M. E.; Blomberg, S.; Hellman, A.; Grönbeck, H.; Gustafson, J.; Martin, N. M.; Balmes, O.; van Rijn, R.; Andersen, J. N.; Deppert, K.; Bluhm, H.; Liu, Z.; Grass, M. E.; Hävecker, M.; Lundgren, E. Phys. Rev. B: Condens. Matter Mater. Phys. 2011, 83, 115440. 
(32) Lundgren, E.; Gustafson, J.; Mikkelsen, a.; Andersen, J.; Stierle, a.; Dosch, H.; Todorova, M.; Rogal, J.; Reuter, K.; Scheffler, M. Phys. Rev. Lett. 2004, 92, 046101.

(33) Martin, N. M.; Van den Bossche, M.; Hellman, A.; Grönbeck, H.; Hakanoglu, C.; Gustafson, J.; Blomberg, S.; Johansson, N.; Liu, Z.; Axnanda, S.; Weaver, J. F.; Lundgren, E. ACS Catal. 2014, 4, 3330-3334.

(34) Datye, A. K.; Bravo, J.; Nelson, T. R.; Atanasova, P.; Lyubovsky, M.; Pfefferle, L. Appl. Catal., A 2000, 198, 179-196.

(35) Farrauto, R. J.; Lampert, J. K.; Hobson, M. C.; Waterman, E. M. Appl. Catal., B 1995, 6, 263-270.

(36) Xiao, L.-h.; Sun, K.-p.; Xu, X.-l.; Li, X.-n. Catal. Commun. 2005, 6, 796-801.

(37) Colussi, S.; Gayen, A.; Farnesi Camellone, M.; Boaro, M.; Llorca, J.; Fabris, S.; Trovarelli, A. Angew. Chem., Int. Ed. 2009, 48, 8481-8484.

(38) Thevenin, P.; Pocoroba, E.; Pettersson, L. J.; Karhu, H.; Väyrynen, I. J.; Järå s, S. J. Catal. 2002, 20\%, 139-149.

(39) Kinnunen, N. M.; Hirvi, J. T.; Venäläinen, T.; Suvanto, M.; Pakkanen, T. A. Appl. Catal., A 2011, 397, 54-61.

(40) Reimann, S.; Stötzel, J.; Frahm, R.; Kleist, W.; Grunwaldt, J.-D.; Baiker, A. J. Am. Chem. Soc. 2011, 133, 3921-3930.

(41) Waser, J.; Levy, H. A.; Peterson, S. W. Acta Crystallogr. 1953, 6, 661-663.

(42) Becker, E.; Carlsson, P.-A.; Grönbeck, H.; Skoglundh, M. J. Catal. 2007, 252, 11-17.

(43) Becker, E.; Carlsson, P.-A.; Kylhammar, L.; Newton, M. A.; Skoglundh, M. J. Phys. Chem. C 2011, 115, 944-951. 